\title{
California ponders cell-banking venture
}

State agency grapples with technical and ethical challenges.

\section{BY ERIKA CHECK HAYDEN}

$\mathrm{I}$ nvestigators creating a wealth of adultderived stem-cell lines may soon get new banks for storing them. Unlike stem cells derived from human embryos, induced pluripotent stem (iPS) cells face few political and ethical hurdles because they can be produced from adult tissue. As a result, investigators have created a rash of iPS-cell lines representing a huge range of genetic variations.

Now, one of the biggest funders of stem-cell research, the California Institute for Regenerative Medicine (CIRM) in San Francisco, is contemplating ways to organize these efforts. The agency is holding a trio of meetings this week to consider funding iPS-cell banking projects. This is a welcome development for scientists hoping to use the cell lines to test responses to new drugs and, eventually, to grow replacement tissues for treating degenerative diseases.

"We're creating these lines without really having a process to distribute them, and without really knowing whether people want to use them," says Jeanne Loring, an iPS-cell researcher at the Scripps Research Institute in La Jolla, California. "For the most part, iPS-cell banking efforts are fragmentary."

CIRM is not the only organization trying to change that. On 20 April, the public-private Innovative Medicines Initiative in Brussels announced that it is considering funding an iPS-cell bank. And in Japan, Shinya Yamanaka - the researcher at Kyoto University who ignited the field with his breakthrough creation of iPS cells from mice in 2006 - is developing a bank using the premise that cells taken from 50 carefully selected donors would be immunologically matched to $90 \%$ of the Japanese population.

In the United States, some banking efforts are already under way, such as one funded by the state of Massachusetts; some institutions, such as the Harvard Stem Cell Institute in Cambridge, also distribute lines created by their investigators. CIRM may build on an existing effort by the US National Institute of Neurological Disorders and Stroke (NINDS) in Bethesda, Maryland, which is banking iPS cells derived from people with three neurodegenerative diseases at the Coriell Institute for Medical Research in Camden, New Jersey.

But to succeed, CIRM and other would-be bankers must tackle some important issues. For a start, researchers use many different methods to generate iPS cells. A potential cell bank would need to decide how to handle such heterogeneity, because it affects the potential uses of a cell line.

The cell lines themselves also vary widely, especially in their pluripotency - their ability to develop into a range of tissues. And because studies have shown that iPS cells can acquire mutations during the reprogramming process and while they are in culture, an iPS-cell bank would need to monitor them constantly using genomic tests.

NINDS has tackled some of these issues through its banking project, which is depositing 25 iPS-cell lines in a small repository at the Coriell Institute. Coriell carries out a battery of tests on cell lines submitted to the bank, such as chromosome typing to monitor the potential accumulation of mutations. It is also subjecting each line to a set of genomic and epigenomic tests for pluripotency, which "Wave been developed "We'recreating by Kevin Eggan, a these lines stem-cell researcher without really at Harvard Univerhaving a process sity in Cambridge, to distribute Massachusetts. CIRM them." looks set to emulate this approach by using a 'scorecard' of assays to characterize each line in its bank.

Perhaps more complicated than the scientific issues are the policy issues, such as what level of consent should be required from individuals who donate cells. Such issues are "on the same order of complexity as the issues surrounding derivation and use of human embryonic stem cells", says stem-cell researcher Roger Pedersen of the University of Cambridge, UK. Although iPS cells do not require the destruction of an embryo, the work that is done with them could yield private genetic information or great commercial benefit - both of which are potential concerns for the living adult from whom the cell line is derived.

CIRM has dedicated one of the meetings this week to these ethical issues. Given the scale of the questions - and the hope that CIRM's efforts will smooth the way for other cell banks - others in the field will be watching closely. 